\title{
Proposal for a Trustworthy Behavior Model Based on Interviews Concerning Corporate Integration
}

\author{
Takashi MATSUURA $^{\mathrm{a}^{*}}$, Nobuyuki KOBAYASHI ${ }^{\mathrm{b}}$, and Seiko SHIRASAKA ${ }^{\mathrm{a}}$ \\ ${ }^{a}$ Graduate School of System Design and Management, Keio University, \\ 4-1-1 Hiyoshi, Kohoku-ku, Yokohama-shi,Kanagawa, 223-8526 Japan \\ ${ }^{b}$ The System Design and Management Research Institute of Graduate School of System Design and Management, \\ Keio University, 4-1-1 Hiyoshi, Kohoku-ku, Yokohama-shi, Kanagawa, 223-8526 Japan
}

\begin{abstract}
Japanese companies have begun integrating their businesses to reduce costs and increase competitiveness. In a previous study, we interviewed subjects who had experienced corporate integrations to clarify how organizational design could be implemented during integrations. Results revealed many conflicts among integrated companies but not how integration leaders could recognize conflict and trust behaviors and cultivate trust. This study completes that previous study and shows how the conflict and trust cultivated via corporate integration relate to items in the trustworthy behavior model. We organize interview results and the nine major types of interdepartmental conflicts. Then we map conflict-handling modes and show relations between interview results and conflict types, interdepartmental conflicts, and conflict-handling modes in tree diagrams for each interviewee. As with conflict, we map interview results concerning trust and the trustworthy behavior. Finally, this study indicates factors of perceived trustworthiness, trustworthy behavior, and risk-taking in relationship in a tree diagram. Interviews clarify that the trustworthy behavior model proposed by Matsuura et al. relates to actual corporate integration.
\end{abstract}

Keywords: Trust, Trustworthy Behavior, Conflict, Corporate Integration

\section{Introduction}

Many Japanese companies have begun integrating their businesses to reduce costs and increase competitiveness [1]. Although Matsuura et al. [2] proposed a Trustworthy behavior model (TBM), they did not show how conflict is connected to Trust and Trustworthy behavior, nor did they show how people in charge of a corporate integration could recognize Conflict and Trust. Therefore, the aim of this study is to clarify how Conflict is connected to Trust and Trustworthy behavior within TBM by showing how people in charge of a corporate integration could recognize Conflict and Trust within TBM. We show that the TBM [2] is relevant to actual corporate integrations and that it can aid practitioners in the future.

We explain the novelty of this study as follows. Previous studies describe frameworks and mechanisms of organizational conflict, model conflict types, and discuss approaches to conflict management. Thomas [3] defined conflict as a process. Pondy [4] described the dynamics within an episode of conflict. Thomas [5] presented a twodimensional taxonomy of conflict-handling modes. These studies, however, offered no solutions for conflicts that arise and persist in following corporate integrations.

Mayer et al. [6] described a Trust model that encompasses three characteristics of the trustee party and Risk-taking by the trustor party but presented no behaviors that cultivate Trust. Whitener et al. [7] provided an exchange framework that mapped out Trustworthy behaviors and provided a method for the trustee party to

*Corresponding author: t.matsuura@sdm.keio.ac.jp cultivate trust. However, it did not include Risk-taking by the trustor party.

Nor did previous studies describe the relation between Conflict and Trust. Ayoko et al. [8] modeled interactions among Conflict types (Task, Relationship, and Process), Features of Conflict (Intensity and Duration), open Communication, and workplace Trust. They analyzed via linear regression hypotheses concerning each relation and the mediating and moderating effects. They did not, however, offer solutions for Conflict and ways to cultivate Trust by internalizing Trustworthy behaviors.

Walton et al. [9] categorized conflicts that occur among units within an organization into nine major types of Interdepartmental conflict as described below. Conflict is also categorized into three Conflict types (Task, Process, and Relationship). However, Walton et al. [9] did not clarify the relationship between Conflict types and the Interdepartmental conflict.

Mayer et al. [6] described factors of perceived Trustworthiness of a trustee (Ability, Benevolence, and Integrity). Trustworthiness of the trustee helps certain people to build the foundation to develop Trust in the organization. Furthermore, Mayer et al. [6] showed a loop connection from the factors of perceived Trustworthiness, Trust, Risk-taking in relationship, and outcomes.

Whitener et al. [7] described that managerial behavior is an important factor influencing the development of trust in the relationship between managers and employees. In particular, they define managerial Trustworthy behavior as volitional actions and interactions performed by managers that are necessary although not sufficient, to

Received: April 1, 2020

Accepted: October 15, 2020 
engender employees' trust in them. In explaining Trustworthy behavior, they cited Integrity and Benevolence of among Mayer et al.'s [6] factors of Trustworthiness and discussed the relationship of these two factors with trust. However, they did not clarify whether all Trustworthy behaviors ware related to Trustworthiness.

Matsuura et al. [2] applied previous research to trustortrustee relationship and proposed the TBM that resolved the issue of corporate integration. Matsuura et al. [2] created the TBM combining with previous research; however, in actual corporate integration, they did not show how to recognize Conflict, Trust, Trustworthy behavior, and how trustor recognizes Trustworthy behavior of the trustee to cultivate Trust.

Therefore, the novelty of this study is to clarify the relationship between Conflict types and Interdepartmental conflict, and the relationship between Trustworthiness and Trustworthy behavior based on the common points extracted from the interview of practitioners engaging in corporate integration. That is because in an actual corporate integration of three companies, if there are any Conflicts among people involved in the integration, those practitioners would have experienced Conflict-handling.

Furthermore, to obtain the synergies of merging three companies into one, practitioners would minimize misunderstanding among employees. Additionally, we point out that Trust should be cultivated with Trustworthy behavior among the three companies for successful corporate integration. That is because if there is no mutual Trust among employees, they would hide their inconveniences from each other when we confirm whether employees continue the corporate activities without causing negative impacts after the integration.

This study proceeds as follows. Section 1 describes components of the TBM [2] in previous studies and their correspondence to tables and figures that organize interview results. Section 2 discusses Conflicts and efforts to mitigate them revealed in interviews with five managers experienced with corporate integrations. Section 3 organizes Trust, Trustworthiness, Trustworthy behavior, and Risk-taking in relationship in the tree diagrams. Section 4 describes that the components of TBM are involved in corporate integration. Section 5 presents the conclusions and future prospects.

\subsection{The research methodology of this study}

The interviews toward practitioners, and tables and tree diagrams for the proposed method would be adapted as research methodology in this study. That is because the categorization based on the TBM about the contents of the interview results such as Conflict, Trust, and Trustworthy behavior would show the relation among those contents.

In order to categorize the contents of the interview result, the interviews were conducted in the following consideration: interviewing people involved in the actual corporate integration, interviewing people in different positions individually, and interviewing at the timing after the integration. Following the above conditions, we interviewed five people who experienced the 2011 integration of Companies A, B, and C, to confirm their activities of some sort of Conflict-handling modes.

In order to clarify the relationship between Conflict types and Interdepartmental conflict, this study shows how to create tables and tree diagrams. We set the classification of the previous study and the interview results in the table columns and rows. In this study, we refer to the Interdepartmental conflict shown by Walton et al. [9] to classify the interview results. Next, in the tree diagram, we reclassify Conflict types (Task, Process, and Relationship), following Ayoko et al. [8] which is cited from Jehn [10].

The results of the interview on people involved in corporate integration indicate the relationship between Conflict types and Interdepartmental conflicts shown in tables and tree diagrams. Furthermore, we add Conflicthandling modes to the relationship among Conflict types and Interdepartmental conflicts, to show the relationship between Interdepartmental conflict and Trust via Conflict types. As a result, we show the relationship of correspondence with Conflict-handling modes to reduce conflict.

In order to clarify the relationship between Trustworthiness and Trustworthy behavior, we describe how to create the tables and tree diagrams. We set the classification of the previous study for Trustworthy behavior in the columns and that of the interview results in the rows of the table. This study shows (1) the connection among Trust, Trustworthy behavior, and interview results, and (2) the connection between Risktaking, and interview results. From (1), the indicated correspondence among the classification of previous studies would be leaded.

Another indication from (1), the interview results express the relationship among the classifications of multiple previous studies in a tree diagram. However, using the common points of the interview results we assume a relationship between Trustworthiness and Trustworthy behavior exists, which has not been clarified in previous studies. Furthermore, (2) shows Risk-taking in relationship the interview results correspond to.

From the above findings, this study adopted the table and tree diagram to show the relationship among Trust, Trustworthiness, Trustworthy behavior, Risk-taking, and the interview results of people involved in corporate integration. We describe the relationship among these components and Trust. Adopting this research methodology, we show the relationship between the interview results and the components such as Conflict, Trust, Trustworthiness, and Trustworthy behavior shown in the TBM.

To indicate the decision, we put a check mark in the tables to show the relationship between the components of the previous studies and the interview results.

Meanwhile, in the tree diagrams, the relationship among the components of the previous studies and the interview results was shown as a decision. For the decision making on the relationship between the 
components of the previous studies and the interview results, the writer must satisfy the following conditions:

1) Be involved in actual corporate integration.

2) Obtain an understanding of the position of the interviewees at the time of the actual integration and the relationship between stakeholders and interviewee.

3) Obtain an understanding of the intention of interviewee's remarks.

The first condition must be met because if the writer is not involved in corporate integration, he/she will find difficulty in understanding what happened in corporate integration. For the second condition, if the writer does not know the position of the interviewee at the time of actual integration and the position of stakeholders, he/she will not be able to determine the relationship among the organizations of corporate integration. In other words, the interview results cannot be divided into data at the organization level. Lastly, the third condition must be met because if the writer does not understand the intent of the interviewee's results, he/she may make a different decision than the actual interview results. One of the authors in this study has the first-hand experience of the actual corporate integration, so the above conditions are satisfied. Additionally, to determine whether the writer's decision is correct, we confirm the tables and the tree diagrams with the interviewee.

As described above, if we show the relationship between the interview results of the target company and Conflict types, Interdepartmental conflict, and Trust, which are TBM components, TBM may be applied to other corporate integration. However, this study only shows the relationship among the components in the TBM, so the relationship among components in this study and the other components which do not appear in this study would not be indicated in this study. This study does not aim either to show the weight of each components influencing to other components.

Regarding the relationship between the interview results shown in the tables and the components shown in the previous study, and the relationship between each component and the interview results in the tree diagrams, we confirmed the validity in writing or the following contents to the interviewee:

- By putting a checkmark, you agree on the relationship between the components of the previous studies on the tables and the interview results; if you disagree, indicate the reason and suggestions for changes.

- You agree on the relationship between the components of the previous studies and interview results for each item shown in the tree diagrams; if you disagree, indicate the reason and suggestions for changes.

Consequently, we obtained an agreement from the interviewee for all items in tables and tree diagrams.

\subsection{Main components of the model}

We show the concrete procedure accomplishing the research methodology of this study. We interviewed five managers who had participated in the same corporate integration and organized their responses with respect to the author's TBM (Figure 1), as also proposed by Matsuura et al. [2]. Figure 1 shows the original figure of Matsuura et al. [2] with seven component numbers added. Tables and tree diagrams explain how the TBM [2] relates to corporate integrations discussed during interviews by using these numbers.

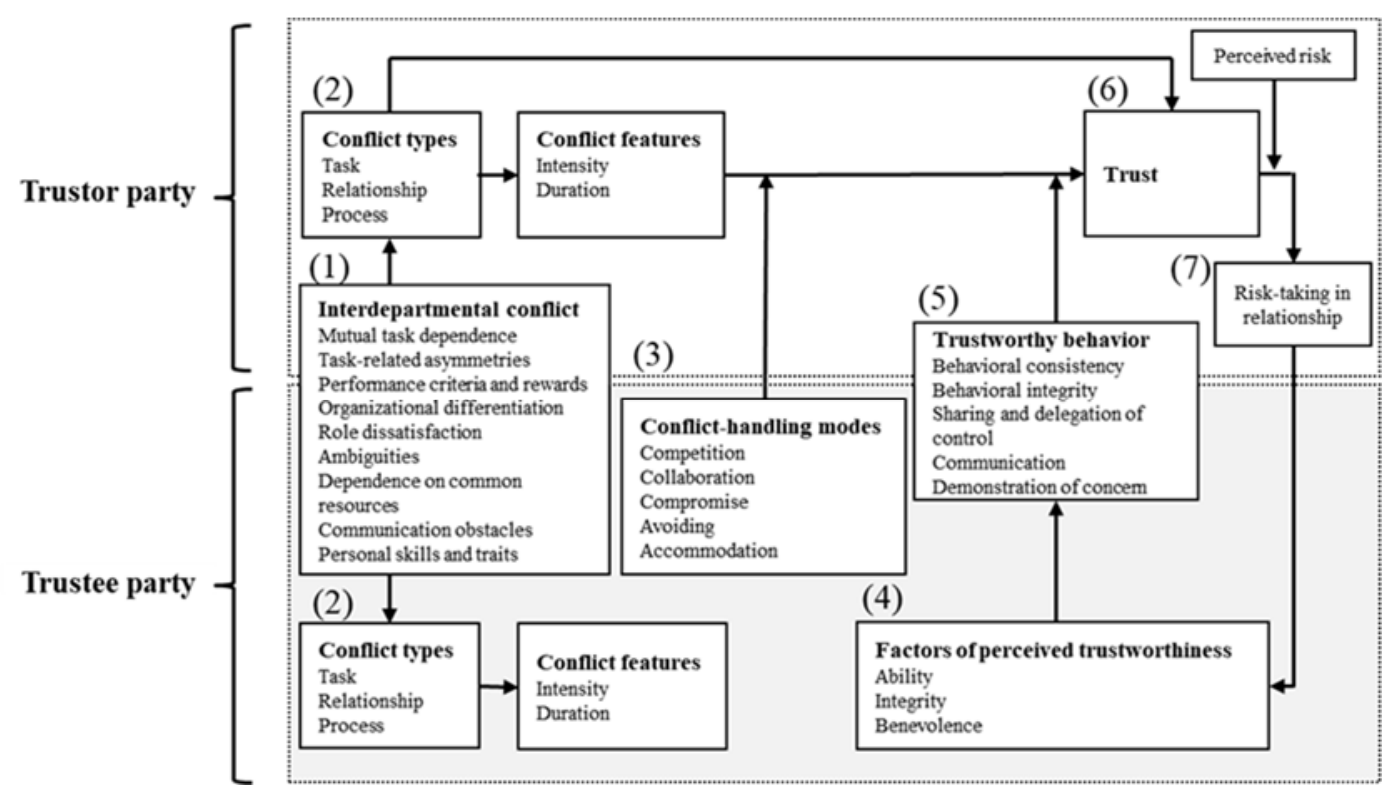

Figure 1 Trustworthy Behavior Model [2]

First, this study shows interviewee's concern with sources of Conflict. We construct a table that aligns interviewees' comments and the nine types of
Interdepartmental conflicts in component (1). Thereafter, we construct another table that aligns interviewees' two different comments for Conflict-handling modes 
concerning component (3). Next, this study shows that Conflict tree diagrams relate the interviewees' comments and Conflict types concerning component (2), Interdepartmental conflict involving component (1), and Conflict-handling modes involving component (3).

Finally, this study applies interviewee's thoughts for Trustworthy behavior of the other party and cultivating Trust. We construct a table that aligns interviewees' two different comments and Trustworthy behavior in component (5). This study shows that Trust tree diagrams relate interviewee's comments and Factors of perceived Trustworthiness from component (4), Trustworthy behavior from component (5), Trust from component (6), and Risk-taking in relationship from component (7).

This study shows that TBM is related to real integration by using these tables and figures.

\section{Interviewees' concerns with sources of conflict}

Companies $\mathrm{A}, \mathrm{B}$, and $\mathrm{C}$ were integrated under Company A, which then employed some 1,000 people. We sought to elicit comments about the integration, its purpose, and its challenges from those involved.

Interviews revealed extensive conflicts associated with the integration. Table 1 relates their comments to Interdepartmental conflicts corresponding to component (1) in Figure 1. Table 2 relates their two different comments to Conflict-handling modes indicated in component (3) in Figure 1. Tree diagrams (Figures 2-6) relates components (1), (2), and (3) of Figure 1 to the interviewees' comments. We clarify the correspondence among Figure 1 and Conflicts of Table 1 and Table 2 arising during actual integration by using the trees.

\subsection{Interviewees}

From August 2017 to January 2018, we interviewed five people who experienced the 2011 integration of Companies A, B, and C. Interviewees from Company A included a president, a senior manufacturing manager, and a senior human resources manager. Interviewees from Companies $\mathrm{B}$ and $\mathrm{C}$ were a corporate officer and a senior engineering manager, respectively. Each interview lasted 90 minutes. Remarks were transcribed and organized.

\subsection{Interdepartmental conflict}

This study relates interviewees' comments to the nine types of Interdepartmental conflict in Walton et al. [9] (Table 1). Thomas [3] defined Conflict as the process that begins when one party perceives that another has frustrated, or is about to frustrate, some of his concerns. Results of the first three interviews are from the president of Company A, describing his feelings before the corporate integration.

The initial field (a1) in Table 1 reflects the president's concerns about pre-integration conflicts arising from difficulty exchanging organizational information. We mapped his concerns as they relate to Task-related asymmetries (column 1), Organizational differentiation (column 2), and Communication obstacles (column 6).

Table 1 Transcribed Interview Notes and Interdepartmental Conflict

\begin{tabular}{|c|c|c|c|c|c|c|c|c|c|}
\hline \multirow{2}{*}{ Transcribed field notes of conflict } & \multicolumn{3}{|c|}{ (1) $\mathbf{I}$} & \multicolumn{6}{|c|}{ Interdepartmental conflict } \\
\hline & 1 & 2 & 3 & 4 & 5 & 6 & 7 & 8 & 9 \\
\hline $\begin{array}{l}\text { (a1) The factory has never been operated collectively, so we will not } \\
\text { know until integration. }\end{array}$ & $\checkmark$ & $\checkmark$ & & & & $\checkmark$ & & & \\
\hline $\begin{array}{l}\text { (a2) When I look at the completed organization design, the organization } \\
\text { appears biased toward headquarters personnel. }\end{array}$ & & & & & & $\checkmark$ & & & $\checkmark$ \\
\hline $\begin{array}{l}\text { (a3) There are people in the factory looking to the right and people } \\
\text { looking to the left. }\end{array}$ & & & & & & $\checkmark$ & & & $\checkmark$ \\
\hline $\begin{array}{l}\text { (b1) The degree to which each manager hierarchy knows the actual } \\
\text { status of their work depends on the organization. }\end{array}$ & & $\checkmark$ & & & & & $\boldsymbol{V}$ & & \\
\hline $\begin{array}{l}\text { (b2) We proceeded with the integration at our discretion, as the top } \\
\text { management did not indicate an integration policy. }\end{array}$ & & & & & $\checkmark$ & & & & $\checkmark$ \\
\hline $\begin{array}{l}\text { (b3) I think the same approach is not always good because the } \\
\text { equipment being manufactured is different. }\end{array}$ & & & & & & $\checkmark$ & $\checkmark$ & & \\
\hline $\begin{array}{l}\text { (c1) The factory strives to reduce man-hours every day, but it has been } \\
\text { configured so that rewards are not obtained according to the results. }\end{array}$ & $\checkmark$ & & & & & & & $\checkmark$ & \\
\hline $\begin{array}{l}\text { (c2) Completely different companies have to collaborate to show what } \\
\text { works for our employees. }\end{array}$ & & $\checkmark$ & & & & $\boldsymbol{V}$ & & $\checkmark$ & $\checkmark$ \\
\hline (c3) Everyone just says good things when integrating. & & & & & $\checkmark$ & $\checkmark$ & & $\checkmark$ & $\checkmark$ \\
\hline (d1) Transferring Company A's load to Company B is not easy. & & & & $\checkmark$ & & & $\checkmark$ & & \\
\hline $\begin{array}{l}\text { (d2) Even if work efficiency is compared, standards and processes } \\
\text { differ depending on factories, and simple comparison is not possible. }\end{array}$ & & $\checkmark$ & & & & & & $\checkmark$ & \\
\hline $\begin{array}{l}\text { (d3) The head office function should have been created separately from } \\
\text { Company A. }\end{array}$ & & & $\checkmark$ & & & $\checkmark$ & & & $\checkmark$ \\
\hline $\begin{array}{l}\text { (e1) There was a difference between Company A's mass production } \\
\text { and Company C's individual production. }\end{array}$ & & $\checkmark$ & & & & & $r$ & & \\
\hline $\begin{array}{l}\text { (e2) We were limited in what we were doing freely with pressure, we } \\
\text { tended to stop saying what we wanted to say. }\end{array}$ & & & & & & $\checkmark$ & & & $\checkmark$ \\
\hline $\begin{array}{l}\text { (e3) When the executives of Company A were unilaterally tough, we } \\
\text { were worried about whether they could work together as a company. }\end{array}$ & & & & & & $\checkmark$ & & & $\checkmark$ \\
\hline
\end{tabular}

Interdepartmental conflicts (second column) are annotated as follows: "1" refers to Task-related asymmetries; "2" refers to Organizational differentiation; " 3 " refers to Dependence on common resources; " 4 " refers to Mutual task dependence; " 5 " refers to Ambiguities; " 6 " refers to Communication obstacles; "7" refers to Personal skills and traits; "8" refers to Performance criteria and rewards; and "9" refers to Role dissatisfaction. 
The second field (a2) in Table 1 notes conflict where he was acting as expected, which, above all, tells us that the president designed the organization with his own decisions. The president expressed concern about conflicts arising from one-sided determinations of roles or an inability to communicate. His concerns are associated with Communication obstacles (column 6) and Role dissatisfaction (column 9). The third field (a3) in Table 1 captures the president's concerns about conflicts arising from ambiguous roles, differing hierarchies, or communication barriers. His statements align with Communication obstacles (column 6) and Role dissatisfaction (column 9). Our subsequent mapping is similarly performed for the remaining four interviewees' statements, that is, the remarks of a senior human resources manager (b1)-(b3), a senior manufacturing manager $(\mathrm{c} 1)-(\mathrm{c} 3)$, a corporate office $(\mathrm{d} 1)-(\mathrm{d} 3)$, and a senior engineering manager (e1)-(e3). In short, Table 1 reveals that a single spoken concern aligns with several categories of potential conflict.

Table 2 Transcribed Interview Notes and Conflict-handling Modes

\begin{tabular}{|c|c|c|c|c|c|}
\hline \multirow{2}{*}{ Transcribed field notes of conflict } & \multicolumn{5}{|c|}{ Conflict-handling modes } \\
\hline & Competition & Collaboration & Compromise & Avoiding & Accommodation \\
\hline $\begin{array}{l}\text { (al) The factory has never been operated } \\
\text { collectively, so we will not know until integration. }\end{array}$ & $\begin{array}{l}\text { (a4) Company A sent a } \\
\text { person to weak areas of } \\
\text { companies B and C. }\end{array}$ & & & & \\
\hline $\begin{array}{l}\text { (a2) When I look at the completed organization } \\
\text { design, the organization appears biased toward } \\
\text { headquarters personnel. }\end{array}$ & & & $\begin{array}{l}\text { (a5) It is necessary to } \\
\text { get a person who is not } \\
\text { a stakeholder but is } \\
\text { calm and transparent. }\end{array}$ & & \\
\hline $\begin{array}{l}\text { (a3) There are people in the factory looking to the } \\
\text { right and people looking to the left. }\end{array}$ & & & & $\begin{array}{l}\text { (a6) The organization } \\
\text { hierarchy is not arranged } \\
\text { vertically but } \\
\text { horizontally. }\end{array}$ & \\
\hline $\begin{array}{l}\text { (b1) The degree to which each manager hierarchy } \\
\text { knows the actual status of their work depends on } \\
\text { the organization. }\end{array}$ & & & & & $\begin{array}{l}\text { (b4) It is important to } \\
\text { know the field and not } \\
\text { fix the organization. }\end{array}$ \\
\hline $\begin{array}{l}\text { (b2) We proceeded with the integration at our } \\
\text { discretion, as the top management did not indicate } \\
\text { an integration policy. }\end{array}$ & $\begin{array}{l}\text { (b5) It is important to } \\
\text { show the direction of } \\
\text { the organization. }\end{array}$ & & & & \\
\hline $\begin{array}{l}\text { (b3) I think the same approach is not always good } \\
\text { because the equipment being manufactured is } \\
\text { different. }\end{array}$ & & $\begin{array}{l}\text { (b6) Enhance each } \\
\text { other's strengths in } \\
\text { integration. }\end{array}$ & & & \\
\hline $\begin{array}{l}\text { (c1) The factory strives to reduce man-hours every } \\
\text { day, but it has been configured so that rewards are } \\
\text { not obtained according to the results. }\end{array}$ & $\begin{array}{l}\text { (c4) The company must } \\
\text { be integrated into one } \\
\text { strong entity that can be } \\
\text { outsourced. }\end{array}$ & & & & \\
\hline $\begin{array}{l}\text { (c2) Completely different companies have to } \\
\text { collaborate to show what works for our employees. }\end{array}$ & & & $\begin{array}{l}\text { (c5) The president } \\
\text { should go around the } \\
\text { field and explain the } \\
\text { policy }\end{array}$ & & \\
\hline $\begin{array}{l}\text { (c3) Everyone just says good things when } \\
\text { integrating. }\end{array}$ & & $\begin{array}{l}\text { (c6) We have to explain } \\
\text { to the other person and } \\
\text { understand deeply. }\end{array}$ & & & \\
\hline $\begin{array}{l}\text { (d1) Transferring Company A's load to Company } \\
\text { B is not easy. }\end{array}$ & & & $\begin{array}{l}\text { (d4) Move the entire } \\
\text { job from factory A to B } \\
\text { or move a person from } \\
\text { factory B to A. }\end{array}$ & & \\
\hline $\begin{array}{l}\text { (d2) Even if work efficiency is compared, standards } \\
\text { and processes differ depending on factories, and } \\
\text { simple comparison is not possible. }\end{array}$ & & & $\begin{array}{l}\text { (d5) Open information } \\
\text { through personnel } \\
\text { exchanges }\end{array}$ & & \\
\hline $\begin{array}{l}\text { (d3) The head office function should have been } \\
\text { created separately from Company A. }\end{array}$ & $\begin{array}{l}\text { (d6) It is natural to } \\
\text { report to the plant } \\
\text { manager closest to the } \\
\text { location. }\end{array}$ & & & & \\
\hline $\begin{array}{l}\text { (el) There was a difference between Company A's } \\
\text { mass production and Company C's individual } \\
\text { production. }\end{array}$ & & & & & $\begin{array}{l}\text { (e4) Since it was a top- } \\
\text { down instruction, I was } \\
\text { aware that I had to do it }\end{array}$ \\
\hline $\begin{array}{l}\text { (e2) We were limited in what we were doing freely } \\
\text { with pressure, we tended to stop saying what we } \\
\text { wanted to say. }\end{array}$ & & & & & $\begin{array}{l}\text { (e5) It was good to have } \\
\text { the opportunity to } \\
\text { explain the business } \\
\text { situation to the top } \\
\text { management }\end{array}$ \\
\hline $\begin{array}{l}\text { (e3) When the executives of Company A were } \\
\text { unilaterally tough, we were worried about whether } \\
\text { they could work together as a company. }\end{array}$ & & $\begin{array}{l}\text { (e6) An executive of } \\
\text { Company A considered } \\
\text { Company C in a friendly } \\
\text { manner, so a trend to } \\
\text { cooperate was } \\
\text { established. }\end{array}$ & & & \\
\hline
\end{tabular}

Table 2 serves two functions with two different comments. First, the transcribed field notes of conflict in Table 2 indicate interviewees' concerns with potential causes of Interdepartmental conflict during integration as Table 1 indicated. Second, it ties five Conflict-handling modes (competition, collaboration, compromise, avoiding, and accommodation) to the dimensions of assertiveness and cooperativeness indicated in Thomas [5]. The president's statement of the first field (a4) expresses concern with Task-related asymmetries, Organizational differentiation, and Communication obstacles as a first potential cause of conflict. The statement aligns with Thomas's [5] categorization as uncooperative and highly assertive and falls under the column labeled Competition in Table 2. The president's statement of the second field (a5) ties to conflicts arising from Communication and Dissatisfaction with roles as a second potential cause of conflict. The statement falls in the mid-range on 
Thomas's [5] spectrum of cooperation and falls under the column labeled Compromise in Table 2. The president's statement of the third field (a6) ties to conflicts arising from Communication and Dissatisfaction with roles as a third potential cause of conflict. The statement ranks as uncooperative and unassertive on Thomas's [5] spectrum and falls under the column labeled Avoiding in Table 2. The senior manufacturing manager's statement of the fourth field (b4) indicates concern with Organizational differentiation and Personal skills as a fourth potential cause of conflict. The statement registers as highly cooperative and unassertive on Thomas's [5] spectrum and falls under the column Accommodation in Table 2.

The senior manufacturing manager's statement of the fifth field (b5) indicates concern with Ambiguities and Role dissatisfaction as a fifth potential cause of conflict. The statement is categorized as uncooperative and highly assertive on Thomas's [5] spectrum and falls under the column labeled Competition in Table 2. The senior manufacturing manager's statement of sixth field (b6) expresses concern with Communication obstacles and Personal skills and traits as a sixth potential cause of conflict. The statement is highly cooperative and highly assertive on Thomas's [5] spectrum and falls under the column labeled Collaboration in Table 2. The above shows five Conflict-handling modes.

Our subsequent mapping is similarly performed for the remaining three interviewees' comments (c4)-(c6) for senior human resources manager, (d4)-(d6) for a corporate officer, and (e4)-(e6) for a senior engineering manager.

\subsection{Conflict tree diagram}

Jehn [10] applied cognitive tree diagrams to memberconflict scenarios, forming Tasks, Relationship, and Process-type conflicts.

The tree diagrams for five interviewees clarify the correspondence among Figure 1 and Conflicts of Table 1 and Table 2 arising during actual integration. Figure 2 shows relations among interview results, Conflict types, Interdepartmental conflicts, and Conflict-handling modes for the president of Company A.

First, this study describes how to depict the tree diagrams with Figure 2. We place "Conflict" at the top, and place and fill in the items at each branch of the tree in Figure 2, as follows:

- First branch: Place Conflict types (2) (Task, Process, and Relationship).

- $\quad$ Second branch: Place one among the nine types of Interdepartmental conflict (1) that related to the interview results mapped on Table 1.

- $\quad$ Third branch: Fill interviewees' comments on Table 2.

- Fourth branch: Fill interviewees' comments that mapped on Table 2, and decide to select one of Conflict-handling modes (3).

Figure 2 shows the result of a description of the tree diagram having three routes of each branch as left-hand side, middle, and right-hand side as follows:

Left-hand side

The arrows go down from Conflict to the interview result.

- First branch: Place "Task" of Conflict types.

- Second branch: Place "Organizational differentiation" in Table 1.

- $\quad$ Third branch: Place the president of Company A's interview results (a1) in Table 2.

The arrow goes up from Conflict-handling modes to the interview result.

- $\quad$ Fourth branch: Place the president of Company A's interview result (a4) and "Competition" of Conflicthandling modes (3) in Table 2.

Middle

The arrows go down from Conflict to the interview result.

- First branch: Place "Process" of Conflict types.

- Second branch: Place "Role dissatisfaction" in Table 1 .

- Third branch: Place the president of Company A's interview results (a2) in Table 2.

The arrow goes up from Conflict-handling modes to the interview result. Fourth branch: Place the president of Company A's interview result (a5) and "Compromise" of Conflict-handling modes in Table 2.

Right-hand side

The arrows go down from Conflict to the interview result.

- First branch: Place "Relationship" of Conflict types.

- Second branch: Place "Communication obstacles" in Table 1.

- $\quad$ Third branch: Place the president of Company A's interview results (a3) in Table 2.

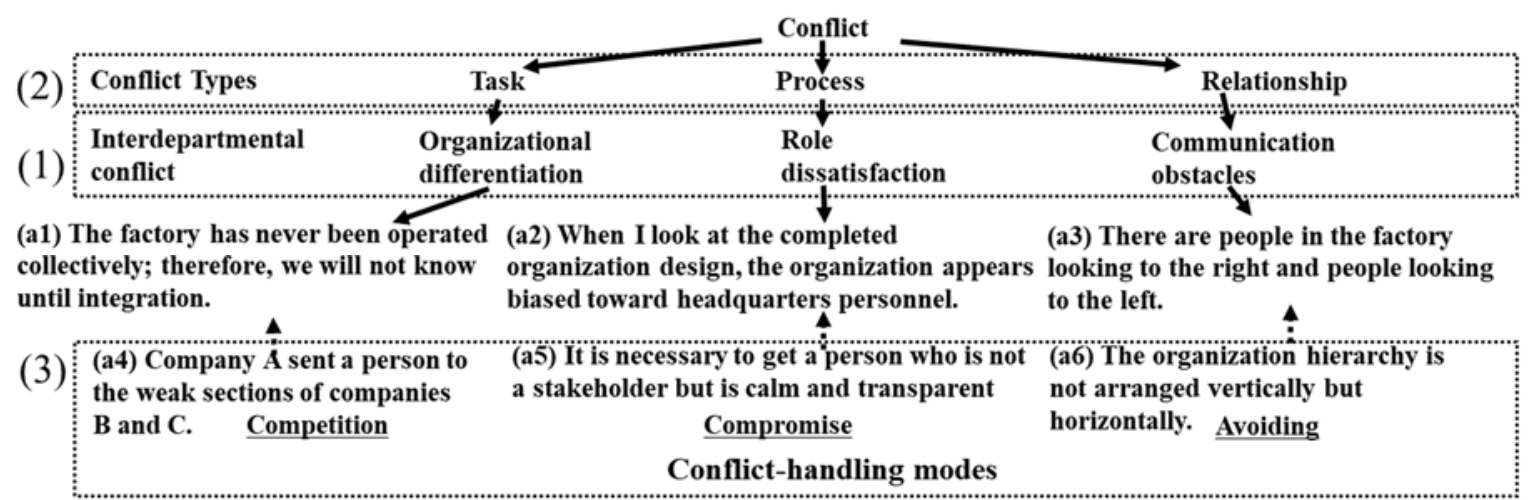

Figure 2 Relationship Among Interview Results, Conflict types, Interdepartmental Conflict, and Conflict-handling Modes (Company A, President) 
- $\quad$ The arrow goes up from Conflict-handling modes to the interview result. Fourth branch: Place the president of Company A's interview result (a6) and "Avoiding" of Conflict-handling modes in Table 2.

Tree diagrams are performed in the same manner for the remaining four interviewees in Figures 3-6. Figure 3 shows a tree diagram for Company A's senior manufacturing manager. Figure 4 shows a tree diagram for Company A's senior manager of human resources. Figure 5 shows a tree diagram for Company B's officer. Figure 6 shows a tree diagram for Company C's senior engineering manager.

Following the above, we find Conflicts in corporate integration and that the interviewees are interested in understanding Conflict-handling modes.

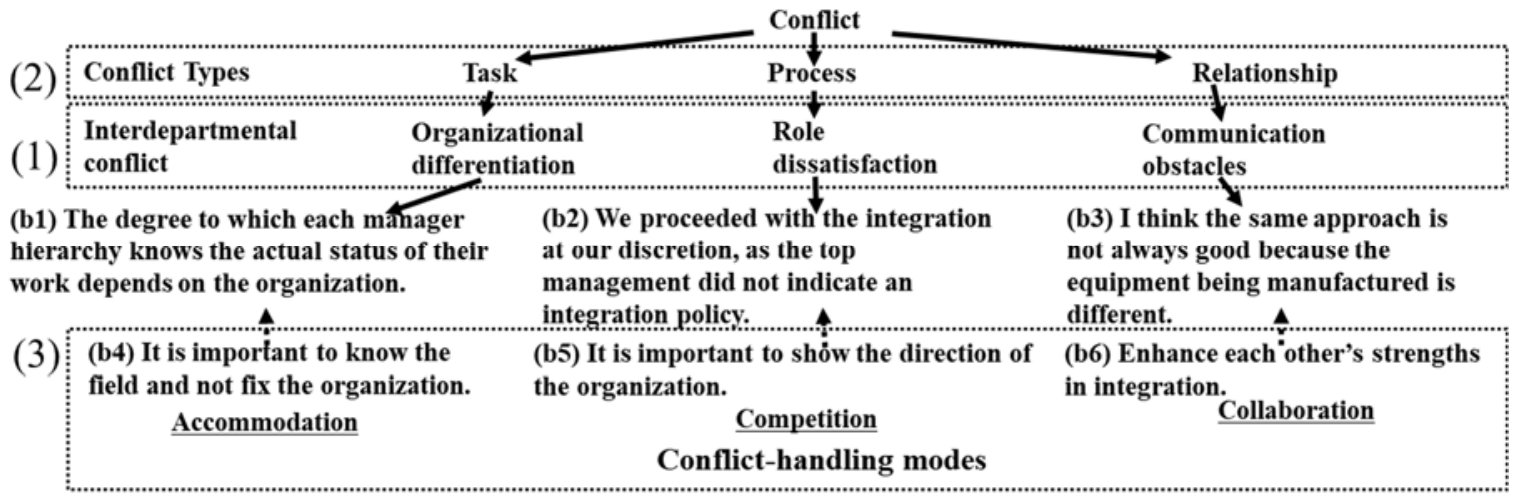

Figure 3 Relationship Among Interview Results, Conflict types, Interdepartmental Conflict, and Conflict-handling modes (Company A, Senior Manufacturing Manager)

\begin{tabular}{|c|c|c|c|c|}
\hline \multirow{2}{*}{ (1) } & \multicolumn{4}{|c|}{ Task $\quad$ Process } \\
\hline & $\begin{array}{l}\text { Interdepartmental } \\
\text { conflict }\end{array}$ & $\begin{array}{l}\text { Performance criteria and } \\
\text { rewards }\end{array}$ & Role dissatisfaction & Ambiguities \\
\hline \multicolumn{3}{|c|}{$\begin{array}{l}\text { (c1) The factory strives to reduce man-hours } \\
\text { every day, but it has been configured so that } \\
\text { rewards are not obtained according to the results. }\end{array}$} & $\begin{array}{l}\text { (c2) Completely different companies (c } \\
\text { have to collaborate to show what } \\
\text { works for our employees. }\end{array}$ & $\begin{array}{l}\text { Everyone just says good things } \\
\text { en integrating. }\end{array}$ \\
\hline (3) & $\begin{array}{r}\text { (c4) The company } n \\
\text { one strong entity th: } \\
\text { Compet }\end{array}$ & $\begin{array}{l}\text { st be integrated into } \\
\text { can be outsourced. } \\
\text { ion }\end{array}$ & $\begin{array}{l}\text { (c5) The president should go around the } \\
\text { field and explain the policy. } \\
\text { Compromise } \\
\text { Conflict-handling modes }\end{array}$ & $\begin{array}{l}\text { (c6) We have to explain to the } \\
\text { other person and understand } \\
\text { deeply. Collaboration }\end{array}$ \\
\hline
\end{tabular}

Figure 4 Relationship Among Interview Results, Conflict types, Interdepartmental Conflict, and Conflict-handling modes (Company A, Senior Human Resources Manager)

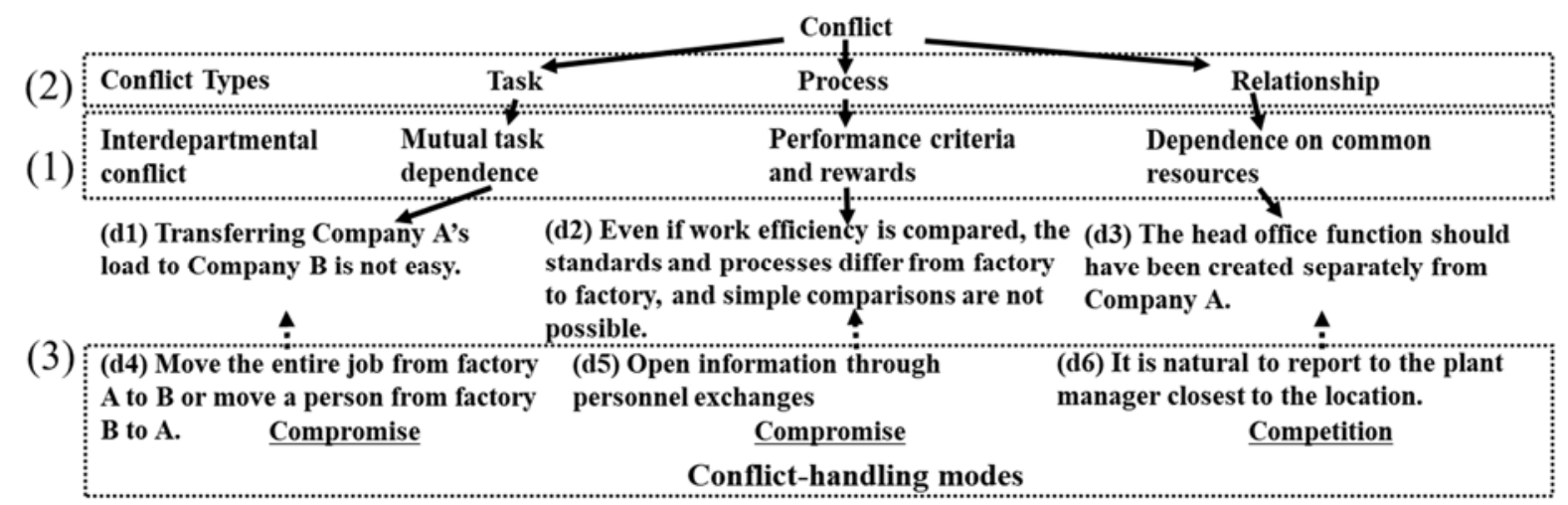

Figure 5 Relationship Among Interview Results, Conflict types, Interdepartmental Conflict, and Conflict-handling modes (Company B, Officer) 


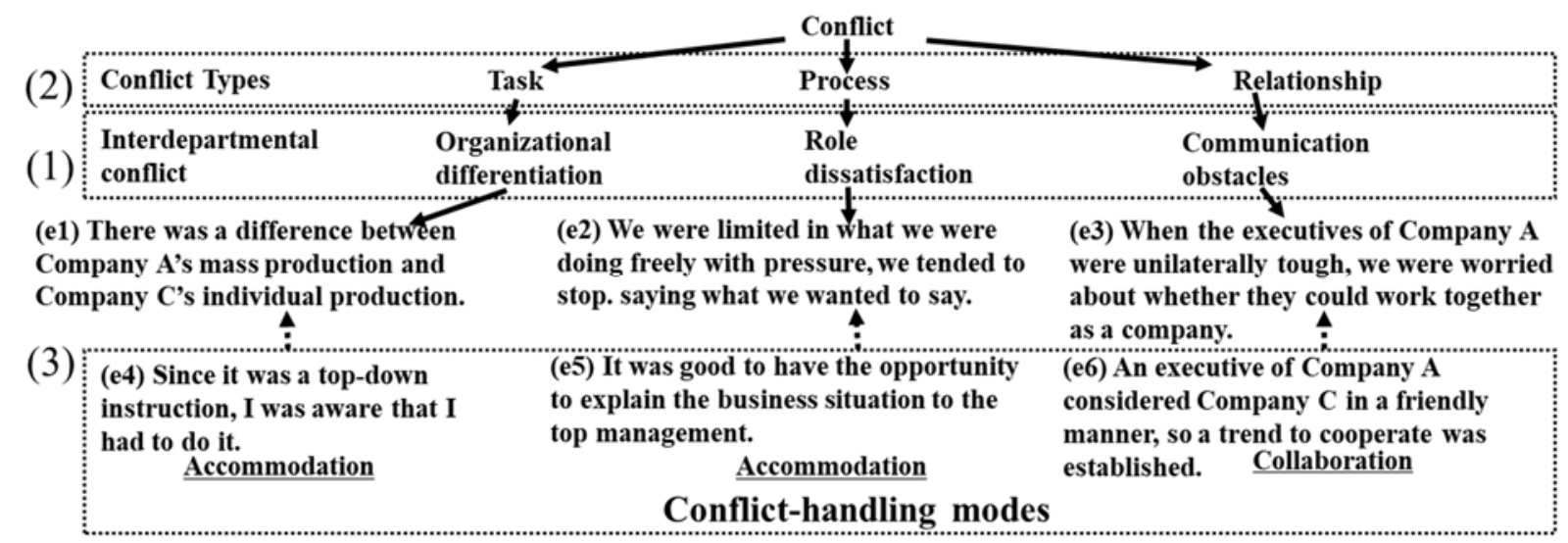

Figure 6 Relationship Among Interview Results, Conflict Types, Interdepartmental Conflict, and Conflict-handling Modes (Company C, Senior Engineering Manager)

\section{Application to trust}

Table 3 summarizes relations between interviewees' comments and the five Trustworthy behaviors (Behavioral consistency, Behavioral integrity, Sharing and Delegation of control, Communication, and Demonstration of concern) in Whitener et al. [7] that correspond to component (5) in Figure 1.

A Company C's senior engineering manager's statement of the first field (e7) denotes Trustworthy behavior in that the trustor party recognized the reform results of Company A were consistently expanded to Company C. We mapped statements associated with "Behavioral consistency" and "Communication". Whitener et al. [7] explains that employees better predict a manager's behavior if he or she acts consistently across time and situations. The reason is that the other (trustee) party expanding reform results of Company A to Company C looks like consistent and Trustworthy behavior from the trustor party.

The Company C's senior engineering manager's statement of the second field note (e8) is that the trustor party has recognized that Company A's executives have recognized Company C's reform efforts. This statement is mapped in connection with "Demonstration of concern" and "Communication." Whitener et al. [7] describes three behaviors to which the counterparties (trustees) respond favorably as follows: showing consideration and sensitivity to employees' needs and interests, acting in a way that protects employees' interests, and refraining from exploiting others for one's own interests.

The president's statement of the last field (a7) denotes Trustworthy behavior that a member of Company B promoted reform by acknowledging Company B's defects. This statement is mapped in connection with "Behavioral integrity" and "Communication." Whitener et al. [7] describes how employees draw inferences about managers' character by observing the consistency between their words and deeds. Additionally, Whitener et al. [7] identifies three factors of "Communication" that affect perceptions of Trustworthiness as follows: accurate information, explanations for decisions, and openness. Therefore, the three transcribed field notes of Trustworthy behavior include "Communication."

Table 3 Relationship between Transcribed Field Notes and Trustworthy Behavior

\begin{tabular}{|c|c|c|c|c|c|}
\hline \multirow{2}{*}{$\begin{array}{l}\text { Transcribed field notes of } \\
\text { Trustworthy Behavior }\end{array}$} & \multicolumn{5}{|c|}{ (5) Trustworthy Behavior } \\
\hline & $\begin{array}{l}\text { Behavioral } \\
\text { consistency }\end{array}$ & $\begin{array}{c}\text { Behavioral } \\
\text { integrity }\end{array}$ & $\begin{array}{c}\text { Sharing and } \\
\text { delegation of control }\end{array}$ & Communication & $\begin{array}{c}\text { Demonstration } \\
\text { of concern }\end{array}$ \\
\hline $\begin{array}{l}\text { (e7) We expanded the reform } \\
\text { results of Company A to } \\
\text { Company C. }\end{array}$ & $v$ & & & $v$ & \\
\hline $\begin{array}{l}\text { (e8) Company A executives } \\
\text { recognized and followed } \\
\text { Company C's reform efforts. }\end{array}$ & & & $v$ & $v$ & \\
\hline $\begin{array}{l}\text { (a7) I was glad that members of } \\
\text { Company B's common } \\
\text { department recognized that its } \\
\text { improvement was not enough and } \\
\text { promoted innovation. }\end{array}$ & & $v$ & & $v$ & \\
\hline
\end{tabular}

\subsection{Trust tree diagram}

This section constructs the Trust tree diagram from the interviewees' comments for Trust with the method explained previously.

First, this study describes how to depict the tree diagrams with Figure 7. We place "Trust" (6) at the top, and place and fills in the items at each branch of the tree in Figure 7, as follows:

- First branch: Place factors of perceived Trustworthiness (4) (Ability, Integrity, and Benevolence). 
- Second branch: Place one among Trustworthy behavior (5) that related to the interview results mapped on Table 3.

- Third branch: Fills interviewees' comments on Table 3.

- $\quad$ Fourth branch: Fill interviewees' comments about Risk-taking in relationship (7).

The first branch spans the three factors of perceived Trustworthiness (Ability, Integrity, and Benevolence) [6]. The second branch spans Trustworthy behaviors (Behavioral consistency, Behavioral integrity, Sharing, and delegation of control, Communication, Demonstration of concern) [7] that relate to interview results. Whitener et al. [7] describes relations their "Demonstration of concern" and Mayer et al.'s [6] "Benevolence", and their "Behavioral integrity" and Mayer et al.'s [6] "Integrity". The fourth branch corresponds to the description of Mayer et al. [6] about Trust as the willingness to assume risk; behavioral Trust is the actual assuming of risk. Therefore, the relationship between interviewee comments and Risk-taking in relationship (7) is selected from the interviewee's (the trustor party's) statements about Trustworthy behavior of the counterparties (the trustee party). Figure 7 shows the result of a description of the tree diagram having three routes of each branch as left-hand side, middle, and righthand side as follows:

Left-hand side

The arrows go down from Conflict to the interview result.

- First branch: Place "Ability" of Trustworthiness.

- Second branch: Place "Behavioral consistency" in Table 3 .
- $\quad$ Third branch: Place Senior Engineering Manager of Company C's interview result (e7) in Table 3.

The arrow goes up from Risk-taking in relationship to the interview result.

- $\quad$ Fourth branch: Place Senior Engineering Manager of Company C's interview result (e9).

Middle

The arrows go down from Conflict to the interview result.

- First branch: Place "Benevolence" of Trustworthiness.

- Second branch: Place "Demonstration of concern" in Table 3.

- Third branch: Fill Senior Engineering Manager of Company C's interview result (e8) in Table 3.

The arrow goes up from Risk-taking in relationship to the interview result.

- $\quad$ Fourth branch: Fill Senior Engineering Manager of Company C's interview result (e10).

Right-hand side

The arrows go down from Conflict to the interview result.

- First branch: Place "Integrity" of Trustworthiness.

- Second branch: Place "Behavioral integrity" in Table 3.

- Third branch: Fill the president of Company A's interview result (a7) in Table 3. The arrow goes up from Risk-taking in relationship to the interview result.

Fourth branch: Fill the president of Company A's interview result (a9).

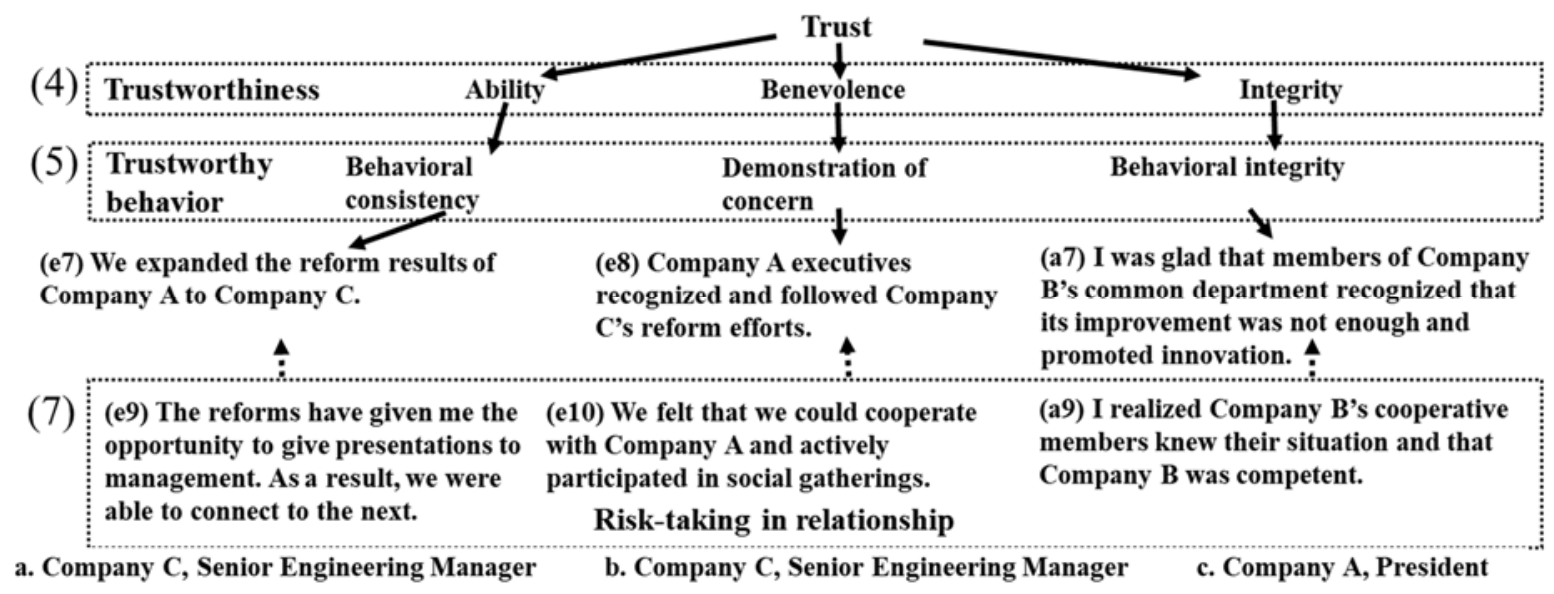

Figure 7 Relationship Among Interview Results, Trust, Trustworthiness, and Trustworthy Behavior

\section{Discussion}

In this section, we consider the description result of the TBM components (Figure 1) with the interview results in corporate integration.

First, we consider the description results of Interdepartmental conflicts corresponding to component (1) in Figure 1. Table 1 shows the five interviewees' comments about Interdepartmental conflicts corresponding to component (1) in Figure 1.
Second, we considered the description result of five Conflict-handling modes corresponding to component (3) in Figure 1. Table 2 shows two functions with two different comments. The comments indicated interviewees' concerns with potential causes of Conflict during integration, and the other comments tied one of the five Conflict-handling modes to the dimensions of assertiveness and cooperativeness. Table 2 shows Conflict-handling modes corresponding to component (3).

Third, we considered tree diagram (Figures 2-6) related components (1), (2), and (3) of Figure 1 to interviewees' 
comments. The trees clarified the correspondence between Figure 1 and Conflicts of Tables 1 and 2 that arise during actual integration.

The three aforementioned relationship among components (1) - (3) in Figure 1 described the Conflict in corporate integration. Ayoko et al. [8] indicated Conflict intensity and Conflict duration in the link between Conflict types and Trust. However, this study does not focus on the Conflict features in corporate integration.

Fourth, we considered the description result corresponding to component (5) in Figure 1. Table 3 summarizes the relations between interviewees' comments and Trustworthy behaviors corresponding to component (5) in Figure 1.

Fifth, we considered tree diagrams (Figure 7) related components (4), (5), (6), and (7) of Figure 1 to interviewees' comments. The trees clarified the correspondence between Trust and Trustworthy behavior of Table 3 during actual integration. The tree revealed that the interviewee (the trustor party) exhibited factors of perceived Trustworthiness and Trustworthy behavior to the other party (the trustee party). Furthermore, the interviewee (the trustor party) had Perceived risk and Risk-taking in relationship with the other party (the trustee party). The tree shows that trust is cultivated in corporate integration. Thereafter, we found that Figure 7 connects to Figure 1.

From the aforementioned, we showed the relations among interviewees' comments and (1) Interdepartmental conflict, (2) Conflict types, (3) Conflict-handling modes, (4) factors of perceived Trustworthiness, (5) Trustworthy behavior, (6) Trust, and (7) Risk-taking in relationship of the TBM (Figure 1).

However, this study only shows the relationship among the components in the TBM, so the relationship among components in this study and the other components which do not appear in this study. Another limitation of this study is that it does not indicate the degree of each component's influence relative to others. Thus, future research needs to clarify the following relationships that are not addressed in this study: relationship between Conflict features and Conflict types, relationship between Conflict features and Trust, relationship between Demonstration of concern toward Trustworthy behavior and that toward Trustworthiness, and a relationship between Demonstration of concern toward Trustworthy behavior and that toward Trust.

\section{Conclusions}

The aim of this study was to clarify how Conflict was connected to Trust and Trustworthy behavior within TBM by showing how people in charge of a corporate integration could recognize Conflict and Trust within TBM. We interviewed five respondents who had conducted corporate integrations with respect to the TBM. Tables and tree diagrams explained how the TBM related to actual corporate integrations as revealed during interviews. We mapped interviewees' comments and the nine types of Interdepartmental conflicts and Conflict- handling modes. Tree diagrams captured relations between interviewees' comments and Conflict types, Interdepartmental conflicts, and Conflict-handling modes expressed by each interviewee. We repeated the procedure for Trust, interview results, and Trustworthy behavior. Finally, we situated factors of perceived Trustworthiness, Trustworthy behavior, and Risk-taking in relationship within tree diagrams. The interviews revealed that the TBM relates to corporate integrations in practice. The results did not, however, show how it could guide future integrations, nor did this study show how to recognize Conflict or cultivate Trust between the trustor party and the trustee party during integrations. Those tasks remain for future studies.

\section{Acknowledgments}

The authors thank Mr. Hirotaka Fujino, who belongs to the System Design and Management Research Institute of Graduate School of System Design and Management, Keio University, for his cooperation.

\section{References}

[1] Japan Fair Trade Commission (2018): List of reports of business combination in 2017, as of December 31, 2017. Obtained from

https://www.jftc.go.jp/dk/kiketsu/toukeishiryo/ichiran_fi les/H29.1901.pdf, accessed on May 1st, 2019.

[2] T. Matsuura, N. Kobayashi, E. Hikishima, and S. Shirasaka: Proposal of Trustworthy Behavior Model. In Corporate Integration. Review of Integrative Business and Economics Research, 9 (S2) (2019).

[3] K. W. Thomas: Conflict and Conflict Management. In D. D. Marvin (ed.), Handbook of Industrial and Organizational Psychology, Chicago: Rand McNally, (1976), 889-935.

[4] L. R. Pondy: Organizational Conflict: Concepts and Models, Administrative Science Quarterly, 12 (2) (1967) 296-320.

[5] K. W. Thomas: Conflict and Conflict Management: Reflections and Update. Journal of Organizational Behavior, 13 (3) (1992) 265-274.

[6] R. G. Mayer, J. H. Davis, and F. D. Shoorman: An integrative model of organizational trust. Academy of Management Review, 20 (1995) 709-734.

[7] E. M. Whitener, S. E. Brodt, M. A. Korsgaard, and J. M. Werner: Managers as initiators of trust: an exchange relationship framework for understanding managerial trustworthy behaviors. Academy of Management Review, 23 (1998) 513-530.

[8] O. B. Ayoko and A. A. Pekerti: The mediating and moderating effects of conflict and communication openness on workplace trust. International Journal of Conflict Management, 19 (4) (2008) 297-318.

[9] R. E. Walton and J. M. Dutton: The Management of Interdepartmental Conflict: A Model and Review. Administrative Science Quarterly, 14 (1) (1969) 73-84. [10] K. A. Jehn: A qualitative analysis of conflict types and dimensions in organizational groups. Administrative Science Quarterly, 42 (1997) 530-557 